\title{
An overview of VIS-NIR Laboratory spectroscopy technique as applied to the analysis of engineering index properties of a geologic material
}

\author{
Bashar, I. L. ${ }^{1}$, Garba, I. ${ }^{2}$ \\ ${ }^{1}$ School of Earth and Environmental Science, University of Portsmouth, United Kingdom \\ ${ }^{2}$ Department of Geology, Kano State University of Science and Technology, Wudil, Kano State \\ Email address: \\ Ibrahim.bashar@myport.ac.uk (Bashar, I. L.)
}

\section{To cite this article:}

Bashar, I. L., Garba, I.. An Overview of VIS-NIR Laboratory Spectroscopy Technique as Applied to the Analysis of Engineering Index Properties of a Geologic Material. International Journal of Science, Technology and Society. Vol. 2, No. 3, 2014, pp. $33-39$. doi: 10.11648/j.ijsts.20140203.11

\begin{abstract}
The paper examine and describe the hypothesis that "the soil spectroscopy is a useful technique in the analysis of engineering index properties of a geologic material, which might lead to a better understanding of the deposit and a full understanding of its engineering geology". Specifically, it was investigated whether spectral techniques can be used to determine material provenance and geotechnical conditions. In the Visible/Near-Infrared (VNIR) and Short Wave Infrared (SWIR), many materials absorb radiation at specific wavelengths, allowing their identification by the position and character of absorption features. This helps in introducing the scientific principles of visible and near reflective spectroscopy with relation to the engineering index properties of a geologic material. The methodology used involves the use of Laboratory investigations which provides valuable information in the geotechnical interpretation and laboratory spectral techniques. This can allowed a study area to be characterized in terms of geology, geomorphology, geotechnical and spectral properties. This paper will therefore present an overview of the visible through NIR (Near infrared) laboratory spectroscopy with a brief summary of theory and application. The research also shows how reflective spectroscopy is as an extremely useful and efficient technique that can be use for the analysis of the engineering properties of a geologic material. The study tries to investigate the effectiveness of soil spectroscopy method on the London Clay Formation.
\end{abstract}

Keywords: Spectroscopy, Engineering Geology, London Clay Formation

\section{Introduction}

In this paper, work the hypothesis that the soil spectroscopy is a useful technique in the analysis of engineering index properties of a geologic material, which might lead to a better understanding of the deposit and a full understanding of its engineering geology. Specifically, to investigate whether spectral techniques can be used to determine material provenance and geotechnical conditions. Spectroscopy can be defined as the study of light that is emitted by or reflected from materials and its variation in energy with wavelength (Smith, 2012). Thus spectroscopy deals with the spectrum of sunlight that is diffusely reflected (scattered) by materials at the Earth's surface using instruments called spectrometers (or spectroradiometers) to make ground-based (field) or laboratory measurements of the light reflected from a test material (Smith, 2012).
The implementation of sustainable agricultural and environmental management requires a better understanding of the soil. It is known that at increasingly finer scales, conventional soil sampling and laboratory analyses cannot efficiently provide this information because they are slow and expensive (Viscarra Rossel and McBratney, 1998a). As pointed out by Grim (1988), prior to the 1920s, geologists making use of some analyses of sediments, listed the finest particles as clay with no identification of what this material actually was. There was no adequate analytical technique for identifying the ultra-fine particles making up the clay material. The first American geologist to specialize in the study of clays was Prof. Heinrich Ries of Cornell University who studied the clay resources of many of the eastern states by describing their ceramic properties (Ries, 1908). In the middle and late 1920s, X-ray diffraction began to be used to identify clay minerals. Several scientists in the United States and Europe published studies 
of clays using X-ray diffraction to positively identify the clay materials (Hendricks and Fry, 1930).

At the present time, much more sophisticated analytical equipment is available to identify and quantify the specific clay minerals present in a sample. Some of the more important analytical techniques that are used include X-ray diffraction, electron microscopy, infrared spectroscopy, and differential thermal analysis. Visible-near infrared diffuse reflectance (vis-NIR) spectroscopy is a fast, nondestructive and requires a minimum sample. Laboratory and field spectroscopy form the basis for imaging spectrometry analysis for a wide variety of disciplines. Geologic materials are well characterized, extensive spectral libraries exist, and there is a good understanding of the nature and source of spectral features in rocks and minerals in the VNIR/SWIR (Kruse, 1980). This paper describes the principles and the process by which vis-NIR spectroscopy can be used to collect soil spectra in the laboratory. Characterisation of soil mineral composition by vis-NIR was simpler and more quantitative than conventional X-ray diffractogram analysis.

Thus the paper is aimed at examining these variations, sample preparations and technique of spectral measurements of samples from the London Clay Formation (the study area) with respect to their Engineering index properties (clay mineralogy). One hundred and eighteen (118) samples were examined by this method to suite the London Clay mineral suite which was proven to be suitable and reliable technique previously used in similar studies (Gibson 2004).

Laboratory based soil characterization require major soil processing, which is time and resource intensive, thus this relentlessly limits application for large-region soil characterization. It is obvious that, if field spectra or remotely sensed spectra of soils are to be used to assess soil properties, it will be necessary to account for the spectral effects resulting from the presence of water in the soil (Philpot, 2002). Thus spectral measurements were taken of the wet and dry samples of the London Clay Formation from the study area with respect to their Engineering index properties (clay mineralogy).

\section{The Study Area and Geological Setting}

The study area (Whitecliff Bay), Figure 1 has a Grid Reference SZ633859 and coordinates (46330,85979 and 464655,86252), East of Isle of Wight, UK. It is accessible through Whitecliff Bay holiday parking place through a public footpath down to the centre of the Bay. The London Clay outcrop (and subcrop) in southern England is restricted to the London Basin and the Hampshire Basin (King, 1981). In the Hampshire Basin due to generally steeper dips, the outcrop is a narrow strip, usually less than $3 \mathrm{~km}$ in width (King, 1981). The outcrop is to some extent covered by Pleistocene or Recent deposits - terrace or valley gravels, glacial deposits or brickearths (King, 1981).

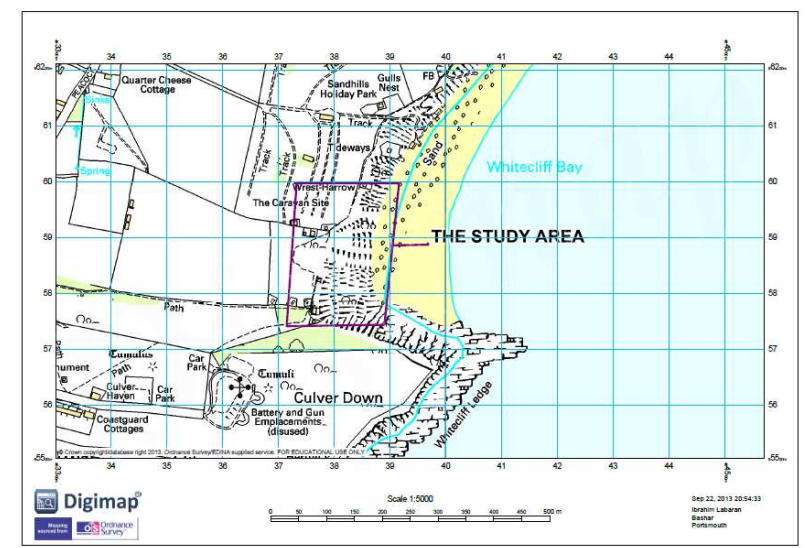

Fig 1. Showing the Location of the study area at Isle of Wight UK.

The Hampshire Basin sits within the tectonic domain defined by the Wessex Basin which underlies much of Southern England. There are two principal geological structures present within the basin, the major E-W structure which is the Purbeck and Isle of Wight Monocline, forming a near-vertical southern rim of the Hampshire basin. The Hampshire Basin is formed over a structural complex basement of a series of blocks that underwent repeat movements during the Palaeozoic and Mesozoic that were covered by Chalk (Yuangdetkla, 2013).

The London Clay Formation comprises the London Clay and Bagshot Sands of previous authors. King 1981 summarised the stratigraphy of the Oldhaven Formation and the London Clay Formation in the London Basin and Hampshire Basin incorporating data from many new temporary exposures and borehole sections. In the Hampshire Basin, divisions $\mathrm{A}$ to $\mathrm{C}$ are recognisable; interbedded sands, mainly at the top of the cycles, are here well developed, and thicken westwards and southwards (King, 1981). The beds previously referred to the Bagshot Sands in the Hampshire Basin are shown to comprise of sand bodies in the upper part of the London Clay Formation and the Lower part of the Bracklesham Group (King, 1981).

Prominent discontinuities, marked usually by pebble-beds, are persistent throughout the Hampshire Basin, and can be correlated with the discontinuities defining the base of division A, B, and C in the London Basin (King, 1981). An understanding of stratigraphy and sedimentology of the Paleogene sequences was essential in determining vertical and lateral changes in lithology that might be expected and thus the potentially relevant engineering characterisation (Yuangdetkla, 2013). The stratigraphical boundary and Sedimentological zonation of the Paleogene, therefore, facilitates determining spatial variations in geotechnical properties across the Hampshire Basin. Hence variation in sedimentary facies is well represented by distinctive lithology.

Typical unweathered London Clay is a firm to very stiff, fissured, dark grey or blue-grey silty clay deposited in a marine shelf environment in a tropical climate during the Eocene (Murray 1974; Sellwood 1981). When weathered, the London Clay is a soft to firm brown clay with ochreous 
staining owing to oxidation of iron compounds. The clay itself may be pale grey or grey-green as a result of leaching (Smith, 1989). In the Hampshire Basin the London Clay is generally more sandy and silty throughout (Jones, 2011).

\section{Principles of Soil Spectroscopy}

The science and technique of reflectance spectroscopy are based on the spectral properties of materials. Certain atoms and molecules absorb energy as a function of their atomic structures (Hunt, 1977 and Goetz et al, 1982). In reflected-light spectroscopy the fundamental property that is of more concern is the spectral reflectance: the ratio of reflected energy to incident energy as a function of wavelength. Reflectance varies with wavelength for most materials because energy at certain wavelengths is scattered or absorbed to different degrees. These reflectance variations are evident when we compare spectral reflectance curves (plots of reflectance versus wavelength) for different materials (spectra of the pure minerals used to estimate soil mineral composition) as illustrated in Figure 2

Each mineral has a distinctive spectral signature, composed of several absorption features, which is a function of composition, crystallinity, concentration, water content and environmental considerations (Hauff, 1983). For mineral identification, the signature is compared against characterized references for a validated identification. This can be done manually by using wavelength tables and overlaying references on the unknown or it can be done using computer algorithms operating against a data base of references i.e. a spectral library (used for identification of mineralogy), for best results these libraries must be set up for specific deposit types (Hauff, 1983).

Although the computer algorithms are useful for data management and organisation, care must be taken when using them for phase identification and quantification (Hauff, 1983).

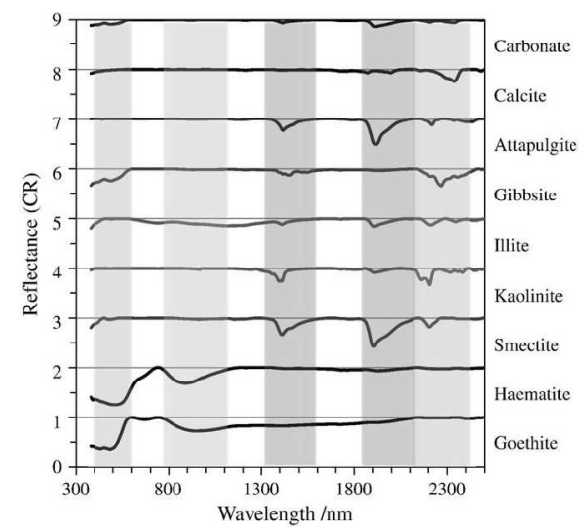

Fig 2. Continuum-removed (CR) reflectance spectra of pure mineral samples, Rossel, 2009.

Distinct downward deflections of the spectral curves mark the wavelength ranges for which the material selectively absorbs the incident energy. The overall shape of a spectral curve and the position and strength of absorption bands in many cases can be used to identify and discriminate different materials.

For example, the determination of clay content by VNIR measurements is achievable in part due to the distinguishing spectral signatures of common clay minerals (Waiser, 2006). The spectral signatures include overtones and combination bands that happen from chemical bonds in soil minerals (Hunt, 1970 and Clark, 1999). For instance, kaolinite, Smectite, and muscovite occur in the clay fraction of soils and have distinct spectral absorption features. Kaolinite [A12Si2O5(OH)4] is an aluminium silicate with two very strong hydroxyl bands near $1400 \mathrm{~nm}$, $\mathrm{OH}$ stretch, and $2200 \mathrm{~nm}, \mathrm{OH}$ stretch $\mathrm{Al}-\mathrm{OH}$ bend combination (Hunt, 1970 and Clark, 1990). Smectite (montmorillonite) $\quad[\mathrm{M}+99 \quad 0.3 \mathrm{Al} 2.7 \mathrm{Si3} .3 \mathrm{O} 10(0 \mathrm{H}) 2$; $\mathrm{M}=\mathrm{Ca} 2+, \mathrm{Mg} 2+, \mathrm{K}+$, etc.] has two very strong water bands around 1400 and $1900 \mathrm{~nm}$ from molecular water and due to molecular water and an AL-OH band at $2200 \mathrm{~nm}$ (Hunt, 1970 and Goetz, 2001). Muscovite $\left[\mathrm{KAl}_{3} \mathrm{Si}_{3} \mathrm{O}_{10}(\mathrm{OH})_{2}\right]$ displays hydroxyl bands at $1400 \mathrm{~nm}$ and between 2200 to $2600 \mathrm{~nm}$ (Hunt, 1970). Iron oxides, hematite and goethite, have absorptions in the visible range of the spectrum. Hematite ( $\mathrm{Fe} \mathrm{O}$ ) has absorption bands at 860, 630, and $450 \mathrm{~nm}$ (Gaffey, 1993). Goethite $(\alpha-\mathrm{FeOOH})$ has absorption bands at 940, 660, and $493 \mathrm{~nm}$ (Scheinost, 1997). A list of some common clay minerals and their corresponding critical wavebands is presented below;

Table 1. Showing clay minerals and their corresponding critical wavebands (Rossel, 2009).

\begin{tabular}{|c|c|c|}
\hline Mineral & $\begin{array}{l}\text { Critical } \\
\text { Wavebands (nm) }\end{array}$ & References \\
\hline \multirow[t]{2}{*}{ Smectite } & 140019002200 & $\begin{array}{l}\text { Hunt and Salisbury, 1970: } \\
\text { Goetz et al., } 2001\end{array}$ \\
\hline & 2206 & Rossel 2009 \\
\hline Illite & 2442 & Rossel 2009 \\
\hline Mica & 140022002600 & $\begin{array}{l}\text { Hunt and Salisbury, } 1970 \text { : } \\
\text { Goetz et al., } 2001\end{array}$ \\
\hline \multirow{2}{*}{ Kaolinite } & 14002200 & Hunt and Salisbury. 1970 \\
\hline & 2207 & Rossel 2009 \\
\hline \multirow{2}{*}{ Hematite } & 450630860 & Gaffey et al., 1993 \\
\hline & 892 & Rossel 2009 \\
\hline \multirow{2}{*}{ Goethite } & 493660940 & Scheinost 1997 \\
\hline & 960 & Rossel 2009 \\
\hline Calcite & 2340 & Rossel 2009 \\
\hline
\end{tabular}

Reflectance spectra in the visible $(400-780 \mathrm{~nm})$ and near infrared (780-2,500 $\mathrm{nm})$ region are as a result of interactions between the radiating energy and the bonds in molecules of soil constituents. In the visible region, the high energy of the radiation causes transitions of electrons between molecular orbits with different energy levels (Rossel, 2009). With lower radiation energy, corresponding to longer wavelengths, the absorption of energy occurs due to vibrations in molecular bonds. Absorption in the NIR region is due to overtones and combinations of fundamental vibrations in the mid-infrared region.

Though Vis and NIR reflectance spectroscopy various methods have been used to relate soil spectra to soil attributes, interpretation of IR spectra is also achieved using functional group frequency tables, computer search of in- 
house and commercial IR spectral libraries and recognition of absorption band patterns gained by experience.

While in the laboratory, soil can be scanned under standard air-dried conditions; it is very difficult to control the water content in the field (Sudduth, 1993). Sudduth (1993), in a laboratory study showed NIR measurements on a wide range of soil moisture tensions. It is perhaps for these reasons that spectroscopic techniques, such as Vis and spectroscopy, are considered as possible alternatives to improve or replace conventional laboratory methods of soil analysis (Janik et al., 1998), also, most of these techniques are non-destructive and therefore allow the protection of the basic integrity of the soil system. In particular, infrared spectroscopy which has been related to soil mineralogy and textural information. Proximal laboratory spectral measurements within the visible-near infrared and shortwave infrared wavelength region can identify clay, sulphates and carbonate minerals (Clark, 1992) common within soils.

\section{Methodology}

The application of this technique will provide key milestones in this research that demonstrate the following:

- Introducing the scientific principles of visible and near reflective spectroscopy with relation to the engineering index properties of a geologic material.

- Describe and review the results of previous studies into rock and soil spectroscopy.

- Describe the design and execution of experiments to investigate (procedure) spectral measurement of samples.

The preparation does not involve any (hazardous) chemicals; it is indeed a non-destructive technique well suited for analyses of some of the essential constituents of the soil (Wetterlind, 2013). The measurements only take a few seconds and several soil properties can be estimated from a single scan. Moreover, the technique allows for flexible measurement configurations and in situ as well as laboratory-based measurements.

Thus for the purpose of this research, the following methodology was proposed for such studies; the data used in the paper were obtained from site investigations undertaken by the authors at Isle of White, UK.

Sampling category and the number of samples taken are all based on the aim of the ground investigation, the geology of the site and the complexity of the geotechnical structure (Eurocode7, 1997). Thus for the purpose of this investigation samples were taken an interval of $1 \mathrm{~m}$ or whenever a change in lithology occurs along the London Clay Formation at Isle of Wight in order to investigate the spatial variation in the spectrometric signature with the engineering index properties of the London Clay Formation.

A total of one hundred and eighteen samples (118) were collected from the study area where each soil core was collected to a maximum depth of $50-80 \mathrm{~cm}$ at an interval of $1 \mathrm{~m}$ along the study area, with the handling, transport and storage of samples conforming to (BS5930:1999, 2010).
Similarly, since the temperature of the sample store is influenced by the climate, the samples were stored at the lowest temperature practicable with the daily temperature variation within the store not exceeding $20^{\circ} \mathrm{C}$. The samples were prepared to be tested for both wet and dry spectral measurements as illustrated below Plate 1.

a) For sample preparation for wet measurements, representative samples from the study area were crushed using Palette knives and hard glass board. Crushed samples were later placed in a 9-cm diameter Petri dish for spectral measurement.

b) For sample preparations for dry measurements, after the wet spectral measurement was conducted, the samples were later oven-dried for 48 hours at $45^{\circ} \mathrm{C}$. The reason of which is to reduce the intensity of bands that are related to water so that signals associated with other soil properties are not masked or hidden (Waiser, 2006).

The samples were further crushed into a much finer form for spectral measurement because additional particle size affects accuracy of the spectral scan (Waiser, 2006) and smaller particles increase reflectance scatter, which reduces the absorption peak height (Workman, 2004), thus the need for soil homogenization while grinding.

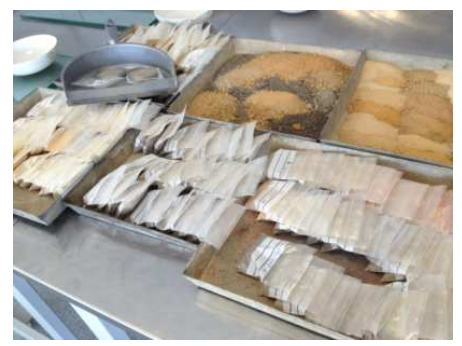

Plate 1. Showing sample preparation for spectral measurement from the study area

Instruments used in measuring and analysing reflectance include;

a) LabSpec 5000, Plate 2, consists of three build-in spectrometers that between them measure the reflected portions of the electromagnetic spectrum, with its accessories (power cable, external fibre cable, a trump attached at $30^{\circ}$ inclined and $5 \mathrm{~mm}$ wide field of view etc.). The instrument has a spectral range between 350 and $2500 \mathrm{~nm}$. The instrument is calibrated with a Spectralon ${ }^{\circledR}$ white reference panel before scanning.

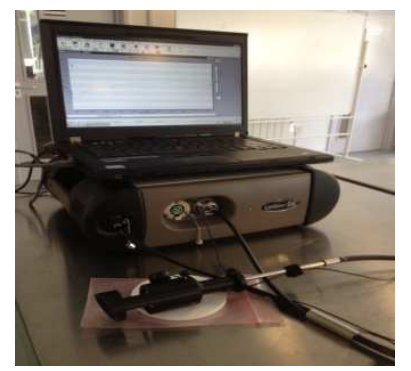

Plate 2. Showing a complete LabSpec 5000 set up for spectral measurement 
a) A (dell) computer laptop used to activate the spectrometer and log measurements using ASD View ${ }^{\circledR}$ software (Indico Pro software) where spectra are collected and saved.

b) ViewSpec Pro program, where ASD spectral data files are saved in binary format and must be converted to ASC11 format using the ViewSpec Pro ${ }^{1}$ program, before being processed by the FSF Excel template. The templates will allow multiple spectral data files to be compiled into a single spreadsheet, scaled for relative and absolute reflectance values or converted to spectral radiance or irradiance values.

c) The Spectral Geologist software TSG, organises spectral data into a single file structure allowing the data and analysis results from a single project, drill hole or geochemical grid to be stored and analysed together in a wide range of mineral exploration environments from around the world. It is customised to target those emissivity features associated with Kaolinite/Smectite, quartz, and its volume scattering fine grained variation (1817). The Spectral Geologist TM (TSGTM, http://www.thespectralgeologist.com/).

d) Oven for drying of soil samples at $45^{\circ} \mathrm{C}$.

e) Palette knives and hard glass board for crushing of samples.

f) A 9-cm diameter Petri dish container to put soil samples for spectra measurement.

\subsection{Test Procedure}

Prepared soil samples (118) were scanned and the reflectance measured using a visible near-infrared spectrometer (LabSpec 5000), having a spectral range of $350-2500 \mathrm{~nm}$, at four different combinations of readings. The essence of which is to account for the spectral effects resulting from the presence of water in the soil. The spectrometer was equipped with a trump attached at $30^{\circ}$ inclined and $5 \mathrm{~mm}$ wide field of view contact probe.

Both wet and dry spectral measurements were conducted separately for 118 samples from the study area the essence is to observe the spatial variation resulting from the presence of water content in the soil (Philpot, 2002). The wet samples prepared from above, then underwent measurement for spectral characterisation. Each specimen was scanned four (4) times with a $90^{\circ}$ rotation between scans, this allows smoothed of any illumination error and thus provides for the consistency of other measurements to be checked (Gibson 2004). This helps to avoid using false replicates in further analyses and also increases the signalto-noise ratio, though this was improved by a longer integration time (the time interval during which energy is collected), a stronger light source or a higher degree of spectra averaging.

The samples were later oven-dried for 48 hours at $45^{\circ} \mathrm{C}$ the essence of which is to reduce the intensity of bands that are related to water so that signals associated with other soil properties are not masked or hidden (Waiser, 2006). After drying, the samples were further crushed into a much finer form for dry spectral measurement because additional particle size affects accuracy of the spectral scan (Waiser, 2006), and smaller particles increase reflectance scatter, which reduces the absorption peak height (Workman, 2004), thus the need for soil homogenization while grinding. The same procedures of spectral measurement for wet samples were followed while taking the measurements for dry samples.

\subsection{Data Processing}

There are several commercial software packages specially developed for analysis and calibrations of spectral data providing easy to use functions for spectral analyses and calibrations (Rossel 2009). This strategy uses a combination of mineral classification systems and spectral parameters processed using Indico Pro software where data are collected and the spectra saved, the ViewSpec Pro ${ }^{1}$ program and The Spectral Geologist (TSG) softwares.

The ASD spectral data files saved in binary format and are converted to ASC11 format using the ViewSpec Pro ${ }^{1}$ program, before being processed by the FSF Excel template. Using TSG, spectra are not treated in isolation, but as a project data set with all the projects ancillary data combined and organised together in a TSG file along with the spectral data. This means that spectral data can easily be analysed in the context of project geology, and this contribute directly to understanding the alteration and mineralisation relationships in the project area. Reflectance measurements of the samples were obtained using TSG spectra which assist in processing and interpreting spectral data.

Check for abnormalities, possible analysis errors was carried out for both the reference and the spectral data. Corrections were applied to the reflectance data to reduce nonlinearities that may exist in the reflectance spectra by deleting the noisy edges.

\section{Results and Discussions}

This strategy represents one of the most effective methods of summarising and presenting relevant information from a large set of spectral data. This involves a top-down approach of three phases.

PHASE 1: Classifying data sets into intervals of broad mineral assemblages.

PHASE 2: Calculating mineral indices (spectral parameters) from the spectral data to measure specific mineral characteristics.

PHASE 3: Integrating associated data sets with the spectral results to analyse and plot trends and relationships.

The important wavelengths in each model were plotted to help establish what portions of the spectra were important for clay content prediction. This is followed by check for abnormalities, possible analysis errors and/or outliers for both reflectance and the spectral data. 
In this research, each sample was analysed for mineralogical composition using the pattern recognition software 'The Spectral Geologist'.

Results of the spectral analysis are further compared to published results and are further interpreted. Although the technique has mainly been used to define end-members for application to image analysis, it is increasingly being used to analyse imagery without recourse to a library of characterized traces.

The mineral composition of the soils from the study area was determined from the spectra average of the four measurements of each soil sample and the determination of clay content by VNIR measurements was achieved due to the distinguishing spectral signatures of common clay minerals.

Results from the spectral analysis test carried out showed that the London Clay mineralogy was dominated by clay groups which includes; Kaolins, White Micas, Smectite, and some invalid (unidentified). The properties of these clays are very different because of differences in their structure and composition. All are extremely fine and contain clay minerals such as Kaolinite WX, Kaolinite PX, Muscovite, Montmorillonite, Gypsum, Aspectral, Muscovitic illite, and Paragonitic illite and non-clay minerals e.g. Iron oxide.

Rossel 2009 reported that spectroscopic measurements can be used to provide a quantitative estimate of mineral composition for the most abundant minerals present in the soil, whereas the interpretation of diffractograms yields only qualitative estimates of mineral abundance. In this case, the sizes of characteristic mineral peaks appearing in the diffractograms, and the assumed crystallinity of these minerals, were used to categorise their abundances into 'minor' $(+)$, 'moderate' $(++)$ and 'major' $(+++)$ classes and are presented in table 2 below;

Table 2. Showing typical mineral composition from the study area at Whitecliff, Isle of Wight, UK.

\begin{tabular}{|c|c|c|c|c|c|c|c|c|}
\hline Mineral & $\begin{array}{c}\text { Reading } \\
\text { Formation } \\
\end{array}$ & $\begin{array}{c}\text { London } \\
\text { Clay A } \\
\end{array}$ & $\begin{array}{c}\text { London } \\
\text { ClayB1 } \\
\end{array}$ & $\begin{array}{l}\text { London } \\
\text { ClayB2 } \\
\end{array}$ & $\begin{array}{l}\text { London } \\
\text { ClayC1 } \\
\end{array}$ & $\begin{array}{l}\text { London } \\
\text { ClayC2 } \\
\end{array}$ & $\begin{array}{c}\text { London } \\
\text { Clay D } \\
\end{array}$ & $\begin{array}{r}\text { Wittering } \\
\text { Formation } \\
\end{array}$ \\
\hline Kaolin WX & & & & & & + & & \\
\hline $\begin{array}{l}\text { Kaolin PX } \\
\text { Muscovite }\end{array}$ & ++ & + & & & + & ++ & +++ & \\
\hline $\begin{array}{l}\text { Montmorillonite } \\
\text { Gypsum }\end{array}$ & +++ & $\begin{array}{c}+++ \\
+\end{array}$ & +++ & +++ & +++ & ++ & ++ & +++ \\
\hline Aspectral & & ++ & + & + & & & & \\
\hline $\begin{array}{l}\text { Muscovite illite } \\
\text { Paragonitic illite }\end{array}$ & $\begin{array}{c}+++ \\
+\end{array}$ & + & & & + & + & & \\
\hline
\end{tabular}

Identification and quantification of clay minerals, particularly those that are responsible for susceptibility of soils to expansion and shrinkage, is a constant focus of research in geotechnical engineering. This research also shows how reflective spectroscopy is as an extremely useful and efficient technique and can be used for the analysis of the engineering properties of a geologic material e.g. the London Clay Formation. A single measurement taking approximately 30 seconds to perform can provide semiquantitative information about the composition and physical state of various units within the study area. Field and laboratory investigations allowed the study area to be characterized in terms of geology, geomorphology, geotechnical and spectral properties. It has been demonstrated using spectral criteria that Smectite are the dominant clay mineral in the mineralogy of the London Clay Formation and is particularly susceptible to shrink-swell behaviour. The data in this study constitute useful guidelines for preliminary foundation designs in the study area.

\section{Conclusions}

The application of soil spectroscopy technique can be seen to aid in the analysis of geologic material engineering characteristics in relation to its mineralogy particularly clay minerals. The reasons why NIRS is being adopted as a preferred analytical method include minimal sample preparation, non-destructive methods, fast simultaneous analysis of constituents, lower staff requirements, costeffective analysis of a single or batch of samples, no hazardous chemicals are needed and results can be very accurate.

This research also shows how reflective spectroscopy is as an extremely useful and efficient technique and can be used for the analysis of a Geologic Formation. A single measurement taking approximately 30 seconds to perform can provide semi-quantitative information about the composition and physical state of various units within the study area. Field and laboratory investigations allowed the study area to be characterized in terms of geology, geomorphology, geotechnical and spectral properties.

Proximal laboratory spectral measurements within the visible-near infrared and shortwave infrared wavelength region can identify clay, sulphates and carbonate minerals common within soils. Recent developments in proximal spectral sensing techniques offer the possibility of increasing the speed, and reducing the cost of interpreting soil samples. In particular infrared spectroscopy has been related to soil mineralogy and textural information.

\section{Acknowledgement}

The authors wish to thank Dr Andy Gibson of the School of Earth and Environmental Science, University of Portsmouth, United Kingdom for his support and assistance during the analysis stage of this work. 


\section{References}

[1] (2013, December 27). Retrieved December 27, 2013, from thespectralgeologist: http://www.thespectralgeologist.com

[2] BS5930:1999. (2010). BS 5930:1999 + A2:2010 Code of practice for site investigations. London: Available from: BSI British Standard Institution, Standard Sales, 389, Chiswick High Rd, ISBN 9780580646096.

[3] Clark, R. e. (1990). High spectral resolution spectroscopy of minerals. Journal of Geophysical Research, vol.95 , 53-80.

[4] Clark, R. (1999). Spectroscopy of rocks and minerals, and principles of spectroscopy. In N. Rencz, Remote Sensing for the Earth Science: Manual of Remote Sensing (pp. 3-52). New York: John Wiley \& Sons.

[5] Eurocode7. (1997). Eurocode 7 - Geotecnical design-Part 2 Ground investigation and testing.

[6] Gaffey, S. J. (1993). Ultraviolet, visible, and near-infrared reflectance spectroscopy: Laboratory spectra of geologic materials. In C. Pieters, Remote geochemical analysis elemental and mineralogical composition (pp. 44-70). Cambridge: University of Cambridge Press.

[7] Gibson, A. (2004). Ph.D Thesis: Spectral properties and characterisation of Debris from the Black Ven Landslide complex, Dorset, England. Portsmouth: University of Portsmouth.

[8] Goetz, A. (2001). Field reflectance spectroscopy for detection of swelling clays at construction sites. Field Anal. Chem. Technol. Vol5, pp146-150.

[9] Goetz, A. (1982). Mineral identification from orbit: Initial results from the shuttle multispectral infrared radiometer. Dec 3; 218(4576):1020-1025.Links.

[10] Grim, R. (1988). The history of the development of clay mineralogy. Clay Mineralogy, 36, 98-110.

[11] Hauff, P. (1983). An overview of VIS-NIR-SWIR field spectroscopy as applied to precious metals exploration. Arvada, Colorado: Spectral International Inc., 80001303 4038383

[12] Hendricks, S. (1930). The results of X-ray and microscopic examination of soil colloids. Soil Science, Vol.29, 450-480.

[13] Hunt, G. S. (1970). Visible and near-infrared spectra of minerals and rocks.I. Silicate minerals. Modern Geology 1 (4), 285-250

[14] Hunt, G. (1977). Spectral signatures of particulate minerals in the visible and near infrared. Geophysics , 42, 501-513.

[15] Jones, L. (2011). Modelling Volume Change Potential in the London Clay. Quarterly Journal of Engineering Geology and Hydrogeology, v.44, p.109-122.

[16] King, C. (1981). The stratigraphy of the London Clay and associated deposits. Rotterdam: Dr.W.Backhuys,Publisher.
[17] Kruse, F. Mineral mapping using spectroscopy: From field measurements to airborne and satellite-based image spectrometry. Reno Nevada: Arthur brant laboratory for exploration geophysics, department of geological science and engineering, university of Nevada.

[18] Murray, J. (1974). Palaeogene foraminiferida and palaeoecology, Hampshire and Paris Basins and the English Channel. Palaeoecology Special Paper, vol.14.

[19] Philpot, W. (2002). Spectral Reflectance of Wetted Soils. New York, pp1-2: Cornell University.

[20] Ries, H. (1908). Clays-their Occurrence, Properties and Uses.2nd Edition. New York: John Wiley and Sons, Inc,.

[21] Rossel, V. (2009). In situ measurements of soil colour, mineral composition and clay content by vis-NIR spectroscopy. Global Journal of Soil Science , 253-266.

[22] Scheinost, A. (1997). VIS-NIR reflectance spectra of goethite $(\alpha-\mathrm{FeOOH})$ as a function of particle size, unit-cell size, and cation substitution. In Lunar and Planetary Science XXVIII. Houston: Lunar and Planetary Institution.

[23] Sellwood, B. (1981). Mesozoic and tertiary argillaceous units: distribution and composition. Quarterly journal of Engineering Geology and Hydrogeology, vol.15, 264-270.

[24] Smith, B. (2012). Introduction to Hyperrspectral Images. Lincoln, Nebraska: Microimages, inc.

[25] Sudduth, K. (1993b). Soil organic matter, CEC and moisture sensing with a portable NIR spectrophotometer. Transaction of the American Society of Agricultural Engineers, vol 36, $1575-1580$.

[26] Viscarra Rossel, R. (1998a). Soil chemical analytical accuracy and costs:implication from Precision Agriculture. Australian Journal of Experimental Agriculture , 38 764774 .

[27] Waiser, T. (2006). MSC Thesis: In Situ Characterization of Soil Clay Content with Visible Near-Infrared Diffuse Reflectance Spectroscopy. Texas: A\&M University.

[28] Wetterlind, J. e. (2013). Soil Analysis Using Visible and Near Infrared Spectroscopy. In Plant Mineral Nutrients:Methods and Protocols, Methods in Molecular Biology (pp. 95-106). Springer Science+Business Media, vol.953 LLC D01 10.1007/978-62703-152-3 6.

[29] Workman, J. (2004). Understanding and using the nearinfrared spectrum as an analytical method. In C. Roberts, Near-infrared spectroscopy in agriculture. (pp. 13-25). Soil Science Society of America.

[30] Yuangdetkla, K. (2013). Ph.D THESIS: DISTRIBUTION OF LANDSLIDES AND GEOTECHNICAL PROPERTIES WITHIN THE HAMPSHIRE BASIN. Portsmouth: University of Portsmouth, United Kingdom. 